\title{
Announcements and credibility under inflation targeting 2 放
}

\author{
Banu Demir ${ }^{\mathrm{b}}$, Taner M. Yigit ${ }^{\mathrm{a}, *}$ \\ ${ }^{a}$ Department of Economics, Bilkent University, 06800 Ankara, Turkey \\ ${ }^{\mathrm{b}}$ World Bank, Turkey Country Office, Ankara-Turkey
}

Received 17 April 2007; received in revised form 10 January 2008; accepted 6 February 2008

Available online 15 February 2008

\begin{abstract}
We inspect how inflation target announcements are instrumental in building central bank credibility and shaping inflation expectations. Investigating the role of announcements by using a time varying credibility measure, we find that both the accuracy and the frequency of inflation announcements have a positive impact on how much attention the public pays to target announcements.
\end{abstract}

(C) 2008 Elsevier B.V. All rights reserved.

Keywords: Inflation target announcements; Inflation expectations; Learning

JEL classification: E31; E58; E42

\section{Introduction}

Adoption of inflation targeting (IT) is aimed at moderating inflation expectations by not only providing discipline in the setting of monetary policy, but also by improving the communication between the policy makers and the public. If the central bank does not gain the necessary trust to hone the public's inflation expectations toward its announced target, then expectations respond only slowly to the target rate, and the monetary authority fails to eliminate the inflation bias of economic agents. Bernanke, in his FRB speech, emphasizes the importance of central bank credibility "...Clearly there are limits to what talk can achieve; ultimately, talk must be backed up by action, in the form of successful policies... Credibility is not a permanent character-

\footnotetext{
We thank the Scientific and Technical Research Council of Turkey for the research support under the grant SOBAG-105K122. We are also grateful to R. Gürkaynak, C. Saglam, and S. Sayek for their valuable comments. All remaining errors are ours.

* Corresponding author. Tel.: +90 312 2901643; fax: +90 3122665140.

E-mail addresses: bdemir@worldbank.org (B. Demir), tyigit@bilkent.edu.tr (T.M. Yigit).
}

istic of a central bank; it must be continuously earned...". ${ }^{1}$ In our study, we investigate how the announcements shape inflation expectations and how the IT central bank's performance in hitting its announced target influences its credibility.

The literature on credibility of announcements (Cukierman, 1992; Faust and Svensson, 2001; Walsh, 1999, 2003) argues that there are two gains from making announcements, 1) the central bank is able to respond to the supply shocks (without distorting the public's inflation expectation) that only itself observes, and more importantly 2) the public can improve its forecast of the central bank's true preferences. In environments where the public is uncertain about the (weights of the) central bank's reaction function, they will use the target announcements as additional information in forming their inflation expectations. The empirical studies about IT's impact on inflation expectations find that credibility and control over inflation expectations cannot be achieved immediately. Johnson (2002), using a panel of 11 countries, shows that IT leads to declines in inflation forecasts without affecting their dispersion while Fraga et al. (2003) argue

\footnotetext{
${ }^{1}$ Ben S. Bernanke's speech at the Annual Washington Policy Conference of the National Association of Business Economists, Washington, D.C on March $25,2003$.
} 
that IT central banks in emerging markets (with imperfect credibility) have to work harder toward this goal. Only forceful reactions to economic shocks by the central bank will force agents' inflation expectations not to significantly deviate from the target and increase the credibility of the central bank.

In our analysis, we inspect the impact of target announcements to see how they help the public to learn about the central bank's objectives. The hypothesis we would like to test is how "credible" and "stable" announcements change the publics" learning behavior. As the central bank delivers on its announced targets or relays as much information as possible to the public, the public should concentrate their inflation expectations around the announced target. In testing our claims, we use survey data from two early adopters of IT, United Kingdom (UK) and New Zealand (NZ), with sufficient length of data under IT and significant differences between the frequencies of their inflation target announcements. Both countries adopted the IT regime in early 1990s (1993 for UK and 1990 for NZ), giving us at least 13 years of data for our analysis. Aside from the sample length, UK is very different than NZ in having a very stable inflation target with only one change in their target while NZ changed its targets quite frequently (40 changes in the sample period). Using inflation forecasts from both countries and state space methodology, we find that forecasters give more weight to the announcements when they are more accurate and frequently changing. In the next section, we elaborate on the model while Section 3 displays the estimation results. The last section concludes.

\section{Model and methodology}

In our model, we follow Walsh (1999) and assume that in an environment with uncertain policy objectives, central banks realize the potential of their announcements to influence inflation expectations of private agents. These announcements reveal more information to the public on the central bank's intentions and also discipline the central bank by providing a benchmark that will be used in its performance evaluation. In such a setting, Walsh shows that even though the banks don't reveal their private information, their announcements provide means to public to revise their expectations and reduce the inflation bias. His result (page 265) regarding the dynamics of how the announcements are incorporated into the public's expectations could be represented as

$\pi_{t+1}^{e}=\pi_{t}^{e}+\theta_{t}\left(\pi_{t}^{a}-\pi_{t}^{e}\right)+\varepsilon_{t}$

where $\pi_{t}^{e}$ is the inflation expectation, $\pi_{t}^{a}$ is the announcement of the target, and $\theta_{t}$ is the credibility or reputation function. ${ }^{2}$ Such models are analogous to the ones in the learning literature where agents use recursive estimations to form their expectations.

\footnotetext{
${ }^{2}$ Theta could be seen as the ratio of the population believing the central bank's announcement in forming their expectations.
}

For $\theta_{t}$, we use Cukierman's (1992) definition of marginal credibility, also formulated by Faust and Svensson (2001) as minus the absolute value of the difference between the actual inflation rate and the one public actually expects the central bank to deliver. For our model, their formulation implies

$\theta_{t}=-\left|\pi_{t-1}-\pi_{t-1}^{a}\right|$

In other words, the central bank's reputation is dependent on its past performance of delivering the announced target. Using a more general function, $\theta_{t}=-f\left(\pi_{t-1}-\pi_{t-1}^{a}\right)$, approximating it in the second-order around zero $\left(E\left(\theta_{t}\right)=-f(0)-E\left(\pi_{t-1}-\pi_{t-1}^{a}\right) f^{\prime}-\right.$ $\left.E\left(\pi_{t-1}-\pi_{t-1}^{a}\right)^{2} f^{\prime \prime} / 2\right)$ and calculating the variance term using a moving average window enable us to also include previous performances of the central bank in the reputation function. Specifically, we expect to find increasing $\theta_{t}$ as the central bank gains more credibility by hitting its target repeatedly, so the expected signs for $f^{\prime}$ and $f^{\prime \prime}$ are negative and positive, respectively, while $-f(0)$ should be 1 .

In our estimations we use a combination of survey and actual inflation data for UK and NZ. The expectations data for retail price inflation in UK and CPI inflation in NZ are obtained from Consensus Economics. Consensus forecasts are monthly reported expectations for the end of current year and the next year. Using them and realized inflation series $^{3}$, we derive monthly expected rate of inflation for the next 12-months as in Johnson (2003). The calculation results are displayed in Figs. 1 and 2, which show a tight fit in UK of expectations to actual inflation especially after the switch to IT whereas in NZ, the situation is not that clear-cut.

Since the expected inflation and announcement data are observed, we use state space estimation, specifically the Kalman filter method, to estimate our time varying credibility parameter. Kalman filter is quite appropriate for our purposes due to its continuous updating (of $\theta_{t}$ ) during the process of expectations formation. We choose the initial parameter values as 1 for $\theta_{0}$, and 0.9 for its persistence; ${ }^{4}$ and finally we determine the error variances, $\sigma_{\varepsilon}^{2}$ and $\sigma_{v}^{2}$ via a grid search and pick the values that give us the minimum regression standard error.

\section{Results}

As mentioned earlier, an increase in credibility via good inflation performance should lead to stable inflation expectations

\footnotetext{
${ }^{3}$ Monthly frequency data is obtained from Global Financial Statistics (GFS). The CPI series is reported quarterly for NZ, so GFS uses the quarterly values to fill in the missing months within each quarter. We do not perform any interpolations since 1) forecasters use the same quarterly values to update their monthly reported expectations, and 2) interpolation would lead to artificial and possibly incorrect changes in the variance terms. Unreported results using quarterly data, which can be provided by the authors upon request, confirm our monthly findings with slightly larger standard errors.

${ }^{4}$ The fairly large level of persistence in reputations is quite conservative for our sample countries since it implies that the reputation cost of deviations from target are prohibitive. The results are robust to different initial values.
} 


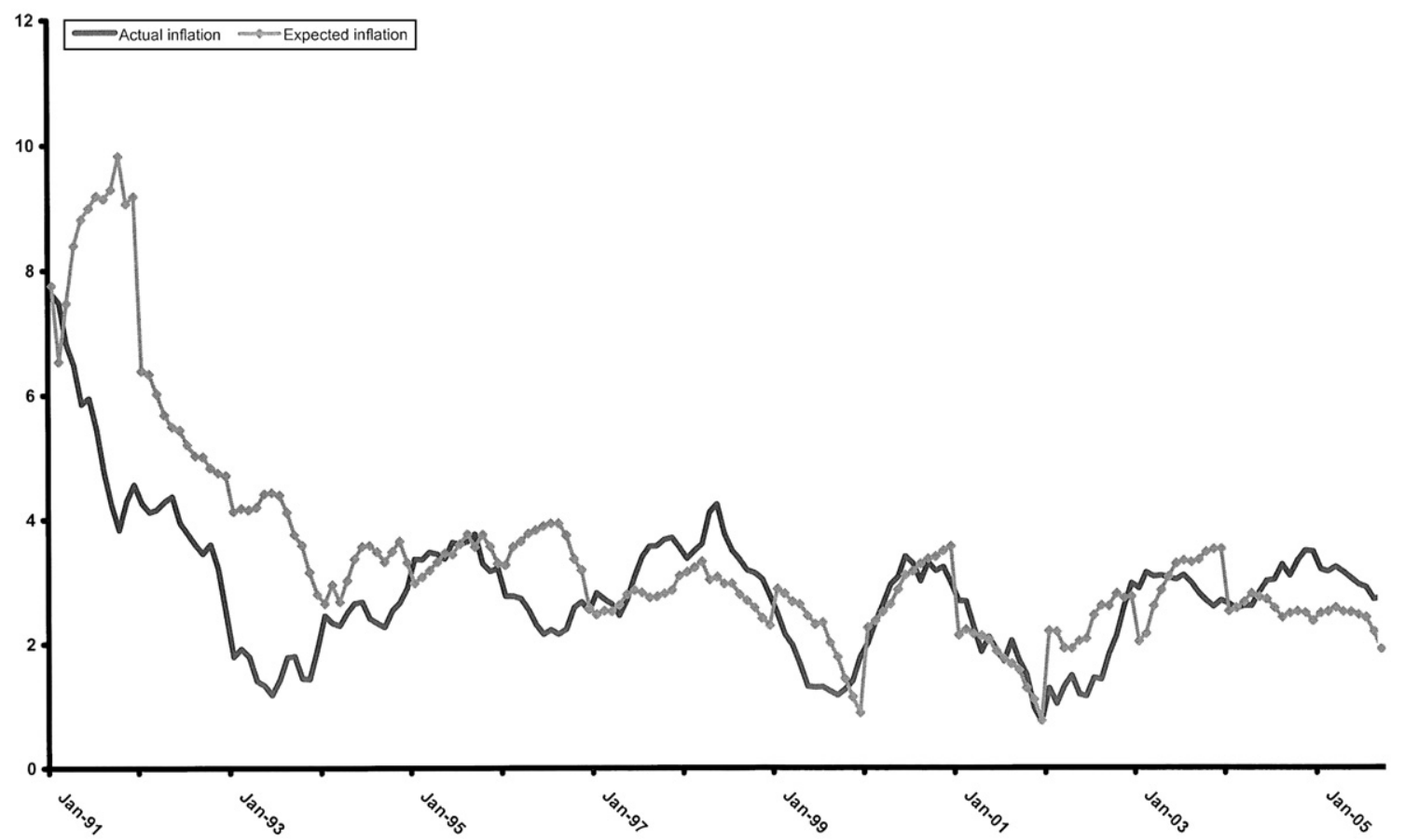

Fig. 1. Inflation and expectations in UK.

and tighter concentration around the announcements, hence an increase in $\theta_{t}$. Using the estimated time-varying values for $\theta_{t}$, we calculate the predicted inflation series, displayed in Figs. 3 and 4. An interesting result of this initial step is the deviation of model predictions from UK inflation survey values around 1997. This occurs right around the Bank of England's (BoE) independence, pointing to increased public uncertainty about the new objective function of the central bank.

Next, we analyze how and why the public changes their learning parameter in response to the central bank's accuracy of

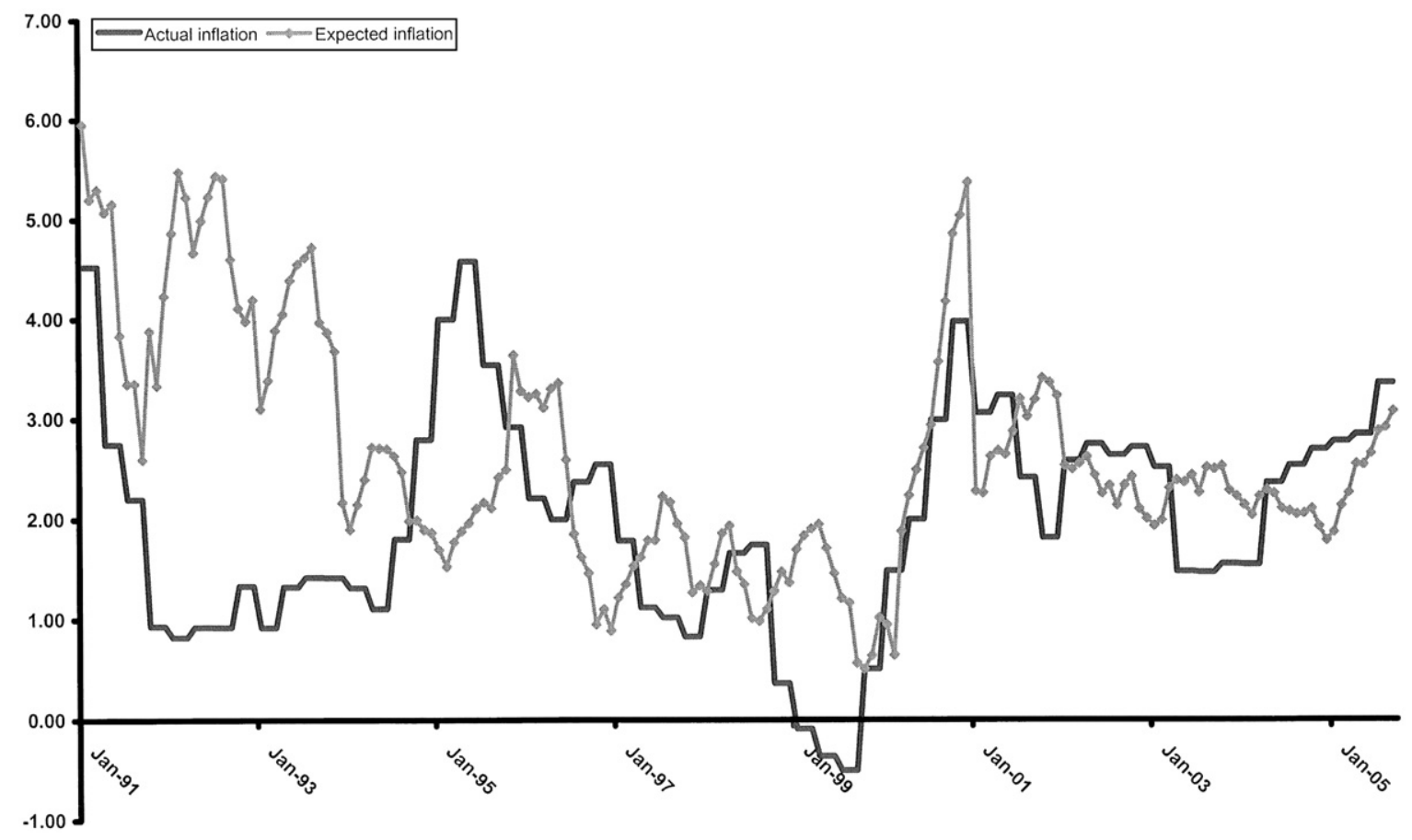

Fig. 2. Inflation and expectations in New Zealand. 


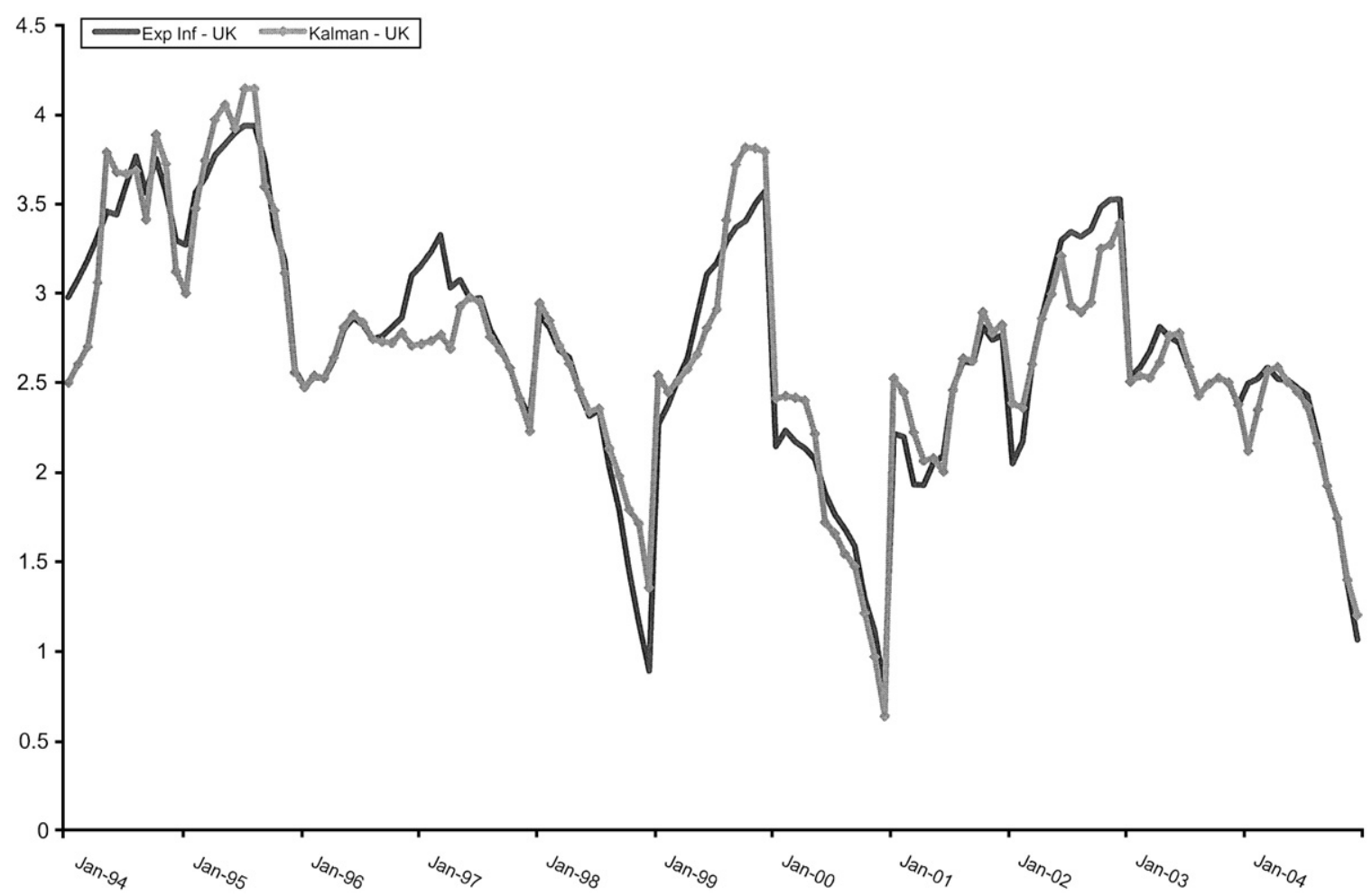

Fig. 3. Survey Inflation Expectations and Kalman Projections - UK.

announcements in mimicking actual inflation and their variability. Therefore, the variables used in the regression are the terms in the approximated credibility function, namely difference of inflation from the announcement $\left|\pi_{t-1}^{a}-\pi_{t-1}\right|$ and the variation of this differential calculated from a 1-year moving window, $\operatorname{var}\left(\pi^{a}-\pi\right)$. We estimate this system of two countries with the help of a dummy variable $D_{\mathrm{UK}}$, which takes the value of 1 for $\mathrm{UK}$ and 0 for NZ. We run a second estimation with a decomposed version of the

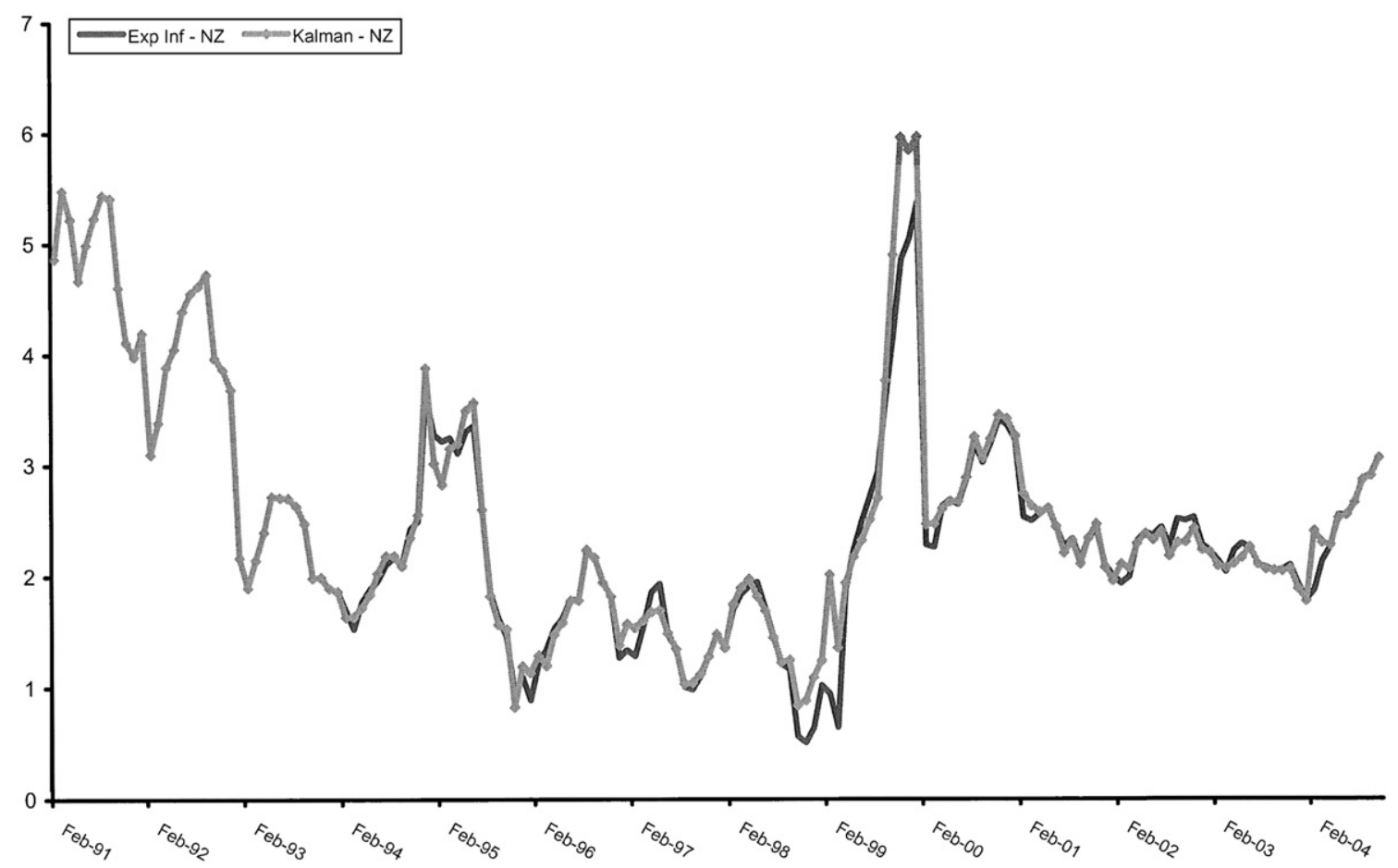

Fig. 4. Survey Inflation Expectations and Kalman Projections - NZ. 
Table 1

Empirical analysis of the time varying parameter $\theta_{t}$

\begin{tabular}{lcc}
\hline & Coeff. & Coeff. (variance broken down) \\
\hline Constant & $0.12^{* *}(0.02)$ & $0.063^{* *}(0.022)$ \\
$D_{U K}$ & $0.17^{* *}(0.03)$ & $0.207^{* *}(0.042)$ \\
$\left|\pi^{a}-\pi\right|$ & $-0.03^{* *}(0.01)$ & $-0.016^{* *}(0.005)$ \\
$\left|\pi^{a}-\pi\right| D_{U K}$ & $-0.31^{* *}(0.03)$ & $-0.322^{* *}(0.030)$ \\
$\operatorname{var}\left(\pi^{a}-\pi\right)$ & $0.03^{* *}(0.01)$ & \\
$\operatorname{var}\left(\pi^{a}-\pi\right) D_{U K}$ & $0.22^{* *}(0.08)$ & \\
$\operatorname{var}\left(\pi^{a}\right)$ & & $10.57^{* *}(2.87)$ \\
$\operatorname{var}(\pi)$ & & $0.129^{*}(0.066)$ \\
$\operatorname{var}\left(\pi^{a}\right) D_{U K}$ & & $-15.45^{* *}(4.38)$ \\
$\operatorname{var}(\pi) D_{U K}$ & & $0.638^{* *}(0.284)$ \\
$n=$ & 318 & 318 \\
$\bar{R}^{2}=$ & 0.31 & 0.36 \\
$F=$ & 29.91 & 26.04 \\
\hline
\end{tabular}

** $\left({ }^{*}\right)$ indicates $95 \%(90 \%)$ significance level. Since $D_{\mathrm{UK}}$ is 1 for UK and 0 for $\mathrm{NZ}, \mathrm{NZ}$ sets the benchmark while interactive terms represent UK. ${ }^{\dagger}$ Due to the stability of the target in UK, the dummy and interactive variance term are very highly correlated. Separate regressions of UK result in even a higher positive coefficient for the variance term. Covariance term is left out of the regression due to its high $(0.98)$ correlation with $\mathrm{NZ}$ target variance.

variance term, into individual variances and covariance. ${ }^{5}$ The estimation results are displayed in the second and third columns of Table 1 . The results show that i) above $35 \%$ of variation in theta is explained by the two moments of the inflation-announcement differential, ${ }^{6}$ and ii) credibility increases with more accurate announcements and less variation in this accuracy. The significantly different first moment coefficients show that the agents in UK value the information content of the past record of $\mathrm{BoE}$ in hitting its targets more than the forecasters in NZ. Decomposition of the variance term illustrates that the more frequent the announcements are the more people pay attention to them. In other words, since BoE has had only one target rate change in the 13 years under IT regime, the past deviations of actual inflation from the target are frequently used by the public in updating their expectations. On the other hand, in NZ, since the targets change extremely frequently, the public focuses more on the announcements than the actual inflation itself, apparent from the positive coefficient on the $\operatorname{var}\left(\pi^{a}-\pi\right)$ parameter. $^{7}$ In short, our estimations show that the announcements carry a large information content in IT regime and their accuracy and frequency influence the extent the public believes in the central bank's announcements and acts accordingly.

\section{Conclusion}

In our study, we examine the credibility performance of central banks under inflation targeting. We use inflation surveys from the UK and New Zealand due to significant dissimilarity between the two countries in the operational application of IT monetary policy. Estimating our model with state space representation of a time varying credibility measure shows that both the accuracy and the frequency of inflation announcements have a positive effect on how much attention the public pays to the target announcements.

\section{References}

Cukierman, A., 1992. Central Bank Strategy, Credibility and Independence. MIT Press, Cambridge, Mass.

Faust, J., Svensson, L.E.O., 2001. Transparency and credibility: monetary policy with unobservable goals. International Economic Review 42, 369-397.

Fraga, A., Minella, A., Goldfajn, I., 2003. Inflation targeting in emerging market economies. NBER Working Papers 10019. National Bureau of Economic Research.

Johnson, D., 2002. The effect of inflation targeting on the behavior of expected inflation: evidence from an 11 country panel. Journal of Monetary Economics 49 (8), 1521-1538.

Johnson, D., 2003. The effect of inflation targets on the level of expected inflation in five countries. Review of Economics and Statistics 85 (4), 1076-1081.

Walsh, C.E., 1999. Announcements, inflation targeting and central bank incentives. Economica 66, 255-269.

Walsh, C.E., 2003. Accountability, transparency, and inflation targeting. Journal of Money, Credit and Banking 35 (5), 829-849.

\footnotetext{
${ }^{5}$ The covariance term is left out of the regression due to its high collinearity with the NZ target variance.

${ }^{6}$ Addition of output gap brings another $5 \%$ explanation of the variation in theta.

${ }^{7}$ The magnitude of the interactive term coefficient for announcement variance in $\mathrm{UK}$ is due to the almost nonexistent variation in the target.
} 